\title{
Evidencias micro y macroespaciales canarias que desmienten la emigración golondrina a Cuba durante el primer tercio del siglo XX
}

\author{
Julio Antonio Yanes Mesa \\ Universidad de La Laguna
}

Con dos fuentes, tan singulares como minuciosas, referidas a espacios geográficos discordantes dentro del Archipiélago Canario, una aludiendo al microespacio que conforma el municipio de Güímar y otra al macroespacio que supone el radio de acción del puerto de Santa Cruz de Tenerife, nos disponemos a replantear el estado de la cuestión que presenta el carácter de la emigración a Cuba durante el primer tercio del siglo XX con el ánimo de verificar si, como sostienen tantos autores, fue estacional en sentido estricto, esto es, "golondrina”. En un principio procederemos a revisar la cuestión a escala local, lo que otorgará a las conclusiones la precisión y exactitud privativa de los microespacios, para luego hacer lo propio a escala insular, con lo que añadiremos la generalización que sólo consienten los macroespacios. Operando de tal manera, pues, podremos soslayar, a un tiempo, los inconvenientes científicos que puedan achacársele a uno y otro tipo de análisis por separado.

Los períodos de estancia y la reincidencia de la afluencia de los canarios a Cuba, durante el primer tercio del siglo XX, han dado cuerpo a una de las cuestiones de más desigual interpretación entre los investigadores de la emigración isleña. Fuentes de la más diversa índole, algunas cuantitativas, como las cifras que publicaba el Consejo Superior de Emigración, y otras cualitativas, caso de las impresiones personales de algún que otro inspector de emigración de la época, manejadas con evidente ligereza por el desconocimiento de los traslados clandestinos y de la infraestructura comunicante Canarias-América, han hecho pensar a más de un especialista en una emigración golondrina, esto es, estacional en sentido estricto. ${ }^{1}$ En el mismo sentido apuntan otras valoraciones coetáneas, tales como el testimonio que, a poco de comenzar la guerra europea, recogió un periódico isleño en Cuba:

“... De las Islas Canarias sale constantemente para la república cubana una numerosa emigración que trabaja en Cuba los seis meses de la zafra —elaboración del azúcary vuelve de nuevo a su lugar de origen para emprender al cabo de otros seis meses

1 Macías Hernández, Antonio: "Un siglo de emigración canaria, 1830-1930”, en Españoles hacia América. La emigración en masa, 1880-1930, Madrid, 1988, pág. 191; y la obra posterior del mismo autor: La migración canaria, 1500-1980, Gijón, 1992, págs. 129 y 149. 
nuevo viaje. Durante los seis meses que trabajan en Cuba los labradores canarios ganan lo suficiente para cubrir sus necesidades, pagar el viaje de ida a Canarias y de retorno a Cuba y mantenerse durante seis meses en su país de origen, más lo que les dejan a sus familias...". ${ }^{2}$

En las páginas que siguen, pretendemos dilucidar la veracidad de esta cuestión hurgando, de manera sucesiva, en sus interioridades a nivel de micro y macroespacio. En un principio, centraremos nuestro esfuerzo en un área tinerfeña muy concreta, el municipio de Güímar, dentro del período cronológico que enmarcan los años 1917 y 1934. Luego, consideraremos el radio de acción de uno de los tres puertos habilitados en las Islas para expedir emigración, el de Santa Cruz de Tenerife, aunque circunscribiendo nuestro análisis al puñado de años que fueron testigos de la guerra europea. Con la pinza que conforman dos estudios afrontados desde ámbitos geográficos tan desiguales, pretendemos obtener un conocimiento científico de la realidad objeto de estudio, toda vez que las conclusiones estarán respaldadas, a un tiempo, por la precisión y la generalidad que distinguen las investigaciones según estén centradas en micro o en macroespacios. Por si fueran pocas las precauciones científicas adoptadas, los dos análisis que, con dirección concomitante, nos proponemos acometer, cuentan de antemano con el inestimable sostén que brinda el cuerpo de conclusiones que reportan otros tantos estudios de la emigración canaria enmarcados en sus propias coordenadas cronológico-espaciales. ${ }^{3}$

\section{Análisis del microespacio que representa el municipio de Güímar}

\section{Aspectos preliminares}

\section{Una fuente que justifica la delimitación espacio-temporal señalada}

La elección de la demarcación territorial que comprende el término de Güímar y de aquellos poco más de quince años no responde, precisamen-

2 La Prensa de Santa Cruz de Tenerife, 11 de noviembre de 1915, pág. 2. Noticias que insisten en el carácter golondrina de la emigración canaria de entonces, también aparecen, por caso, en estos números: 24 de octubre 1910, artículo de "Acuario"; y 13 de enero de 1911, artículo de Francisco González Díaz.

3 Yanes Mesa, Julio Antonio: La emigración del municipio canario de Güímar, 1917-1934, Santa Cruz de Tenerife, 1993; y Crisis económica y emigración en Canarias. El puerto de Santa Cruz de Tenerife durante la guerra europea, 1914-1918, Santa Cruz de Tenerife, 1997. 
te, a un antojo. Una privilegiada fuente del archivo de este municipio tinerfeño, que arrancando en noviembre de 1917 concluye en el mismo mes pero de $1934,{ }^{4}$ cuyos datos no admiten la asimilación con los de otras procedencias en las Islas, ${ }^{5}$ nos ha brindado o, más bien, obligado a constreñir este primer esfuerzo intelectual al marco espacio-temporal mencionado. Se trata de un singular registro en base a cuatro libros sucesivos que, en asientos específicos, recogen a todos y cada uno de los emigrantes que, evidentemente por vía legal, ${ }^{6}$ partieron del municipio en el período que media entre aquellos años. El nombre y apellidos, la edad, el estado civil, el sexo, el domicilio, la fecha de la comparecencia al ayuntamiento y, a partir de 1927, el destino, son los datos más precisos que ofrece nuestra singular fuente de los emigrantes. Como cada asiento, cumplimentado en el momento en que los candidatos a emigrar retiraban la preceptiva cartera de identidad del ayuntamiento, ${ }^{7}$ corresponde a un viaje, de cada individuo aparecen sucesivamente tantos como veces emigró.

Por si fueran pocos los detalles mencionados, cada registro contiene una fotografía del emigrante y, a una o dos columnas, una detallada descripción fisiológica con referencias cualitativas a estatura, corpulencia, color de los ojos y demás señas de identidad. La impresión digital y la firma del titular, o de un testaferro en el caso de los analfabetos, completa el caudal de información que ofrece nuestra excepcional fuente.

4 Los topes, sin embargo, obedecen a circunstancias bien diferentes, pues mientras el inicio de la serie, el 24 de noviembre de 1917, es producto de la conservación del primer libro, el final, el 3 del mismo mes pero de 1934, es fruto del propio ocaso del éxodo.

5 En efecto, la singularidad de esta fuente nos la confirmó quien mejor puede saberlo, el profesor de la Universidad de La Laguna Julio Hernández, que para realizar su tesis doctoral deambuló por todos los archivos municipales de las Islas en busca de registros similares y, éstos sí, generalizados: las comendaticias del siglo XIX.

6 Yanes Mesa, Julio Antonio: "En torno a la importancia de la emigración clandestina en Canarias durante el primer tercio del siglo XX", en Anuario de Estudios Atlánticos, n. ${ }^{\text {41, Madrid-Las }}$ Palmas, 1995, págs. 157-174. La inmensa mayoría emigró dentro de la ley a pesar de la alarmante impresión que tuvieron los contemporáneos, porque operando en este mismo microespacio dedujimos que la emigración clandestina de entonces no alcanzó en el municipio siquiera la quinta parte de la legal.

7 La expedición de carteras de identidad a los emigrantes por los ayuntamientos, aprobada por Real Decreto de 23 de septiembre de 1916, entró en vigor a partir del 15 de mayo de 1917 (véase: La Gaceta de Madrid, anuncio de 25 de abril de 1917). Si la utilización de los libros data de entonces, cosa que creemos razonable pues además coincide con la acentuación de la crisis, y de la emigración, en el municipio por la guerra europea, sólo estaría perdido uno, el que inscribió a los que emigraron entre el 15 de mayo y el 24 de noviembre de 1917 que, a juzgar por los conservados, debe contener un centenar de registros. La expedición de carteras de identidad a los emigrantes, por lo demás, estuvo vigente a lo largo de todo el período que abarca nuestro estudio, pues no fueron sustituidas por un pasaporte de nueva creación hasta comienzos de 1935 (véase: Gaceta de Tenerife, 20 de febrero de 1935, pág. 5). 


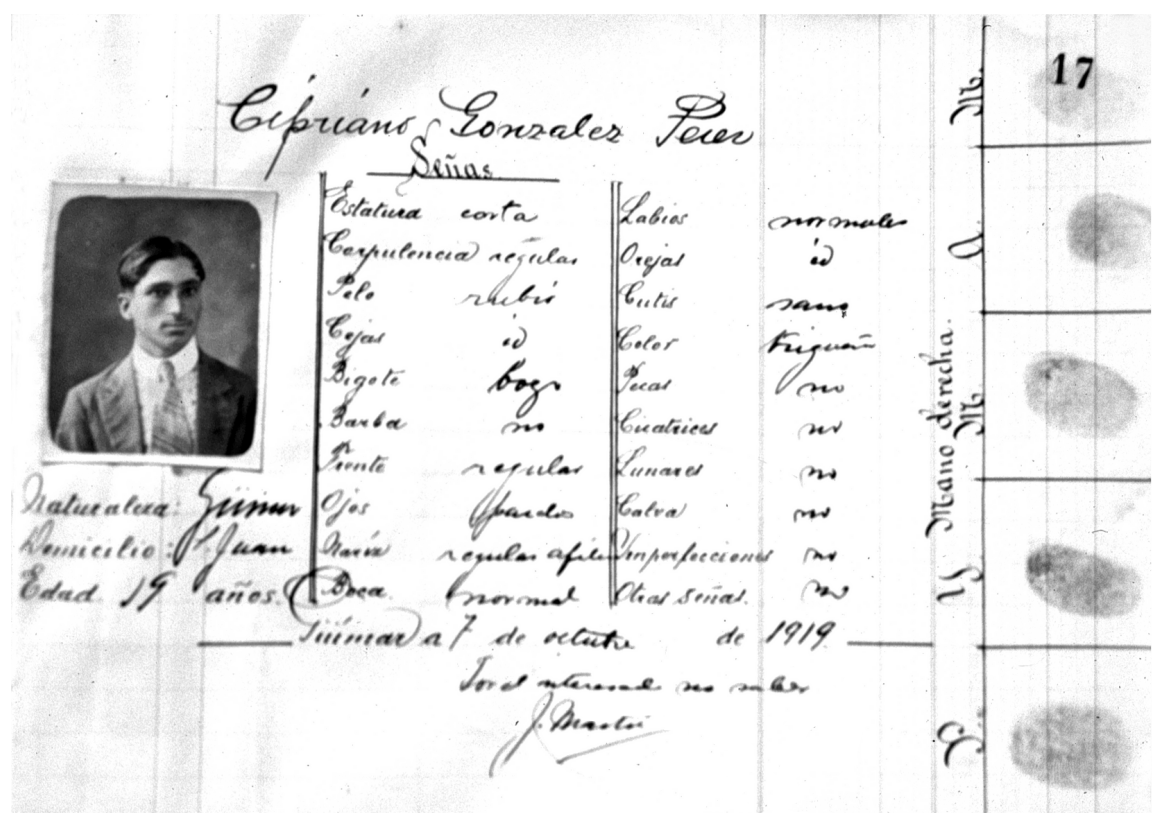

En conjunto, los libros contienen 703 asientos que arrojan un total de 778 emigrantes, fruto de la agrupación de las emigraciones familiares en el registro del cabeza de familia. Si valoramos que 53 (en efecto, sólo 53) inscripciones recogen por segunda, tercera o cuarta vez a individuos registrados en años anteriores por reincidir en la emigración, el número real de los emigrantes, considerando una sola vez a los reincidentes, asciende a 731.

\section{Fuentes complementarias}

En nuestro afán por atar al máximo los cabos de cara a conocer la frecuencia de las idas y venidas a Cuba, en el propio archivo municipal de Güímar nos hicimos con toda la información que, de una u otra manera, delatara la partida, el regreso o, simplemente, la presencia de los emigrantes en el municipio. Es el caso de los oficios de la inspección sanitaria del puerto de Santa Cruz anunciando a las autoridades municipales el retorno, con nombre y apellidos, de algunos emigrantes durante la epidemia gripal de postguerra; de los permisos militares que por las mismas fechas solici- 
taron algunos reservistas para poder emigrar; de los listados vecinales más diversos de la época y, por último, del padrón de 1930, el más próximo de los conservados a nuestros años de estudio. Fuera del archivo municipal, las fuentes orales familiares, al facilitarnos más detalles de la trayectoria de sus miembros emigrados, nos completaron el caudal de información que nos propusimos recopilar.

\section{Metodología}

Nuestra investigación comenzó con la elaboración de una ficha individual de cada emigrante en la que recogimos todos los datos útiles de cara a los objetivos propuestos. A renglón seguido, completamos y verificamos la información de cada ficha, auxiliados por las propias fotografías de los asientos, recurriendo a fuentes orales diversas dentro del municipio. En total detectamos a 549 emigrantes, lo que representa el 70,56\% de los 778 que aparecen, algunos con reiteración, en los libros. Siempre confirmamos la realización de cada emigración, careciendo de relevancia las posibles suplantaciones de personalidad $^{8}$ o la reconsideración de propósitos tras la cumplimentación de los trámites previos. El destino y el carácter de cada emigración, temporal o definitiva, fueron los datos que más nos interesaron recabar para, a continuación, calibrar los períodos de estancia en Cuba de los retornados.

Una vez que concluimos la fase de recogida de información, procedimos a la ordenación alfabética de las fichas de los emigrantes. Fue entonces cuando dejamos en evidencia, de manera rotunda, el carácter de las emigraciones reincidentes $\mathrm{y}$, dado que todos los asientos llevaban la fecha de su elaboración, el intervalo entre unas y otras. Luego, para observar los períodos de permanencia en Cuba de los que emigraron una sola vez, la mayoría, procedimos a la detección de todos ellos en los sucesivos listados vecinales que conserva el archivo. En el sentido contrario, para conocer la fecha previa de partida de los que regresaron al municipio durante la epidemia gripal, relacionados en sucesivos oficios de la inspección sanitaria de Santa Cruz, procedimos a la localización de todos ellos en los libros. Con los mismos propósitos, también seguimos la trayectoria de aquellos emigrantes que, por ser reservistas, pidieron permisos militares por las mis-

8 Yanes: Crisis económica y emigración..., págs. 70-77. En efecto, tal y como confirmamos con posterioridad a nivel de macroespacio, las suplantaciones de personalidad, que no incidían en las estadísticas de la emigración porque los impostores viajaban entremezclados con los restantes emigrantes, siempre fueron muy residuales por la carestía económica y el riesgo personal que conllevaban. 
mas fechas. Finalmente, el padrón de 1930 nos desveló quienes habían regresado y quienes estando aún ausentes aparecían todavía censados en el municipio a finales de la década. Una vez que concluimos nuestra labor de contraste, las conclusiones no nos dejaron ningún resquicio a la duda.

\section{Evolución general del éxodo}

Los primeros datos de nuestros libros, referidos al tramo final de 1917, en concreto a las cinco últimas semanas del año, arrojan un total de 32 emigrantes, lo que a la luz de la restante información nos perfila un contingente emigrado de Güímar durante aquel año próximo al doble centenar de individuos. Dada la tardía incidencia de la crisis en el municipio, ${ }^{9}$ para los tres años bélicos previos, no consideramos descabellada la cifra de cuatrocientos emigrantes. En los años de anteguerra, la inicial expansión del sector frutero en las Islas y, a su vez, el todavía lejano apogeo del azucarero cubano, dejan entrever un éxodo mucho menos intenso, en buena medida circunscrito a los jóvenes para eludir el servicio militar y, a modo de espasmos intermitentes, al resto de la población canaria en función de la incidencia de la sequía sobre los campos isleños.

En 1918, circunstancias tan puntuales como la prohibición de emigrar por la epidemia de gripe española, redujeron el contingente de emigrantes a 51 individuos. Levantada la veda, el recrudecimiento de la crisis isleña durante la postguerra, cuando el sector azucarero cubano alcanzaba su mayor apogeo, disparó la diáspora hasta alcanzar la cifra de 231 emigrantes en $1919 .{ }^{10}$ En 1920, la masiva emigración de los güimareros continuó a niveles espectaculares, pues alcanzó la cota de 174 individuos. En los restantes años, empero, el éxodo acusó una drástica contracción, pues arrojó cifras siempre inferiores a la treintena, salvo en 1923 y 1924, cuando el número de emigrantes ascendió, respectivamente, a 103 y 58, culminando el proceso con la cesación del éxodo en 1934, cuando partió el último emigrante del municipio. La diáspora, pues, describió en su transcurso oleadas decrecientes intercaladas entre otros tantos reflujos.

9 Yanes: La emigración del municipio... págs. 86-91. En efecto, las secuelas de la crisis no se dejaron sentir en el municipio con cierto rigor hasta mediados de 1917. El proceso culminó a comienzos de 1918, cuando el Ayuntamiento, tras comprobar que los ingresos no habían alcanzado siquiera la mitad de lo presupuestado, se declaró en bancarrota y sufrió un embargo por incumplimiento de sus débitos.

10 La Prensa de Santa Cruz de Tenerife, 13 de septiembre de 1919, artículo: "De Güímar. La emigración y las carteras de emigrantes". El espectacular incremento del éxodo provocó el agotamiento de las carteras de identidad de emigrantes en las oficinas municipales. 
Aunque las razones económicas, tanto de expulsión en las Islas Canarias como de atracción en las Isla de Cuba por la contrapuesta evolución de ambas economías, ganaron importancia en el momento culminante del éxodo, la desafección al servicio militar continuó ejerciendo una indudable influencia. Así, nada menos que el 36,25\% del contingente de emigrantes de nuestros años de estudio pertenecía al grupo de edad comprendido entre los 15 y los 20 años, el previo al llamamiento a filas, que ejerció su derecho a emigrar dentro del marco jurídico que establecía la ley. ${ }^{11}$ En contraposición, los emigrantes del quinquenio siguiente, que contenía la edad del llamamiento a filas, apenas representaba el $8 \%$ del contingente, conteniendo además un porcentaje notable de presencia femenina.

\section{Resultados de la investigación}

\section{La evidencia de la inviabilidad de la emigración golondrina}

A la vista de las escasas emigraciones reincidentes que reflejan los libros, apenas 53 que corresponden a un total de 47 individuos, entre las cuales sólo 11 fueron en años consecutivos, queda en evidencia la inexistencia de la emigración golondrina en el municipio. Esas emigraciones reincidentes se reparten entre los cuatro viajes de un emigrante, los tres de cuatro y los dos de cuarenta y dos. El resto, emigró a Cuba una sola vez. Traducidos los datos a porcentajes, tenemos que un $93,51 \%$ del contingente realizó un solo viaje, un $5,79 \%$ dos y un $0,68 \%$ tres o más.

\section{INTERVALO ENTRE LAS EMIGRACIONES REINCIDENTES}

\begin{tabular}{|c|c|c|}
\hline 1 año $\ldots \ldots \ldots 11$ & 5 años ..... 4 & 9 años .. \\
\hline 2 años ....... 10 & 6 años & 10 años \\
\hline 3 años ..... 7 & 7 años & 11 años \\
\hline 4 años .. & 8 años & 12 años \\
\hline
\end{tabular}

Fuente: libros de emigrantes del archivo municipal de Güímar. Elaboración propia.

11 Yanes: "En torno a la importancia...”, págs. 157-174. En efecto, dejando en evidencia la usual homologación de los términos prófugo-emigrante clandestino, los registros de emigrantes del municipio de Güímar nos demostraron que la inmensa mayoría, por no decir la totalidad, de los prófugos había emigrado legalmente tres o cuatro años antes del llamamiento a filas. 
Desechada la dinámica golondrina en la emigración del momento, con el ánimo de detectar los períodos de estancia en Cuba, vamos a prestar atención al intervalo que media entre las distintas emigraciones reincidentes. En principio observamos que sólo hubo 11 emigrantes que acudieron a Cuba a dos zafras seguidas regresando al término de la primera a Güímar. Casi todos ellos, por lo demás, lo hicieron a instancias del espeluznante bienio 19191920, cuando tras regresar al municipio ante las expectativas que abría el cese de las hostilidades en Europa, se encontraron con la dura crisis de postguerra, ${ }^{12}$ lo que unido al apogeo del sector azucarero cubano, debió hacerles partir de nuevo hacia la isla antillana. Ninguno de ellos, por lo demás, volvió a repetir la experiencia en años sucesivos. El resto de las emigraciones reincidentes, también escoradas hacia los años de postguerra, acusan intervalos muy diferentes: 10 estuvieron distanciadas por dos años; 16 por tres o cuatro; 7 por cinco o seis; 5 por ocho o nueve; y 3 , las restantes, por nueve o más años. Aunque el abanico de opciones resulta desconcertantemente amplio, el período de estancia comprendido entre los cuatro-seis años parece, en principio, el más común entre aquéllos que reiteraron en su emigración.

\section{Otros argumentos que insisten en la inviabilidad de la emigración golondrina}

Otros indicios, aunque más fragmentarios, dejan también en evidencia la supuesta existencia de la emigración golondrina. Los oficios remitidos por el inspector de sanidad del puerto de Santa Cruz al alcalde de Guiímar durante la expansión de la gripe española, para que dejara en cuarentena a los emigrantes retornados al municipio en prevención de posibles rebrotes epidémicos, también desmienten esa dinámica estacional. En efecto, ninguno de los 4 emigrantes relacionados en los dos oficios conservados referentes a 1919 y 1920, ni lo hizo al cabo de un año de éxodo, pues no figuraban en los libros, ni volvió a emigrar en años posteriores, pues tampoco volvieron a inscribir registro alguno con posterioridad.

12 Yanes Mesa, Julio Antonio: Leoncio Rodríguez y "La Prensa”: una página del periodismo canario, Santa Cruz de Tenerife, 1995, págs. 162-188. En efecto, tras la firma del armisticio, a la lenta normalización del sector exterior canario por la problemática recomposición de las relaciones exteriores de los países europeos, se unió una prolongada sequía que, arrancando a principios de 1918 tras un temporal de agua y viento, no concluyó, y tras otros aguaceros más apacibles pero también más prolongados que, a corto plazo, causaron más quebrantos que satisfacciones, hasta febrero de 1920. La fuerte crisis que sufrió el sector de subsistencia canario, se tradujo en la escasez y alza generalizada de artículos de primera necesidad en las Islas. 
Ahondando en la inexactitud de la emigración golondrina, el padrón municipal de 1930, con los 132 individuos censados que por entonces estaban ausentes en Sudamérica, de los que 124 residían en Cuba, resulta sumamente esclarecedor. Para calibrar los períodos mínimos de permanencia en la isla antillana, dado que todos ellos permanecían emigrados en 1930, recogimos el nombre y la edad de cada uno con el ánimo de detectar la fecha exacta de cada viaje. Pues bien, de los 132 güimareros ausentes en Sudamérica, en los libros de emigrantes localizamos a 51, mientras que el resto, descontando los escasísimos desplazamientos clandestinos, debió emigrar en fechas previas al primer libro, tal y como evidencia la superior edad de todos ellos. De los localizados, 29 regresaron en los años de la República a Güímar, 11 quedaron definitivamente en América y los otros 11 protagonizaron una trayectoria que no hemos podido reconstruir. Pues bien, de los 29 que regresaron al municipio, 23 permanecieron en Cuba por un período superior a los siete años, lo que nuevamente pone en entredicho la pretendida emigración reiterativa y, más aún, a intervalos anuales.

Al margen de las evidencias reseñadas, datos tan triviales como la mera composición del contingente de emigrantes, donde el grupo dominante era el masculino a edades comprendidas entre los 15 y 20 años, ${ }^{13}$ insiste en la improcedencia de la emigración golondrina. En efecto, ese nutrido sector de población que, evidentemente, estrenaba su derecho a emigrar, de ningún modo pudo proseguir en años sucesivos con idas y venidas anuales a Cuba, pues tuvo vedado su regreso a las Islas, al menos hasta que el Gobierno concedió el oportuno indulto, ${ }^{14}$ por incumplimiento de sus obligaciones militares.

Desechada esa supuesta periodicidad anual e, incluso, la mera reincidencia como pautas definitorias de la corriente emigratoria objeto de nuestro estudio, en las líneas que siguen pretendemos concretar el tiem-

13 Dentro del quinquenio, el grueso de los emigrantes basculaba más hacia los 15 que hacia los 20 años. Por entonces, los mozos recibían el llamamiento a filas a comienzos del año en el que cumplían los 21.

14 La Prensa de Santa Cruz de Tenerife, 19 de diciembre de 1923. En los años de la guerra europea, el gobierno dio un indulto mediante los Reales Decretos de 24 de julio y 15 de septiembre de 1916 y las Reales "rdenes de 1 y 12 de agosto de 1916 y de 24 de marzo de 1917, la última de las cuales concedía una prórroga a los plazos previstos en un principio para que los prófugos, según los casos, tramitaran la redención en metálico o la reducción de su tiempo en filas abonando las cuotas correspondientes. Luego, al menos hasta finales de 1923, cuando los españoles emigrados en América desataron una dura campaña aprovechando el reciente acceso al poder del general Primo de Rivera, el gobierno no volvió a conceder indulto alguno. 
po de permanencia más común de los güimareros desplazados a Cuba, dando por sentado que la mayoría emigró, y temporariamente, una sola vez. En principio, observando que en el padrón de 1930, de los 731 individuos registrados en los libros, sólo quedaban 51 en Cuba en vísperas de la proclamación de la República, deducimos que el resto de los que regresó, unos 500, lo había hecho mucho antes de 1930. Por tanto, estimamos que la duración más frecuente del intervalo emigratorio debió ser relativamente corta, en torno a los cuatro, cinco o, como mucho, seis años. Otras fuentes documentales, aunque muy fragmentarias, respaldan esta hipótesis.

Es el caso de las solicitudes que en 1919 elevaron los güimareros recientemente licenciados del servicio militar a sus jefes para poder emigrar. De las diecisiete concedidas, diez requerían autorización para trasladar su residencia a Cuba, específicamente, por cuatro años; el resto, bien por negligencia o, acaso, porque no pensaban regresar, no temporalizaron la duración de su expatriación. Sin embargo, la trayectoria de unos y otros, detectada por nosotros porque los diecisiete figuraban en los libros de emigrantes, fue similar. Así, todos recibieron la cartilla para emigrar a los pocos días y regresaron, o quedaron en Cuba, en proporciones similares al margen de su supuesta intención inicial. Por tanto, consideramos que esa temporalización de cuatro años revela, más que otra cosa, el intervalo emigratorio que la mayoría consideraba adecuado para cubrir sus objetivos pecuniarios en Cuba a la vista de experiencias previas. Luego, la suerte y los avatares de la vida decidían.

\section{El macroespacio que representa el radio de acción del puerto de Santa Cruz de Tenerife}

\section{Aspectos preliminares}

\section{Una fuente que justifica la delimitación espacio-temporal adoptada}

Como nos ocurriera con el microespacio del municipio de Güímar, la delimitación geográfica que supone la zona de influencia del puerto de Santa Cruz de Tenerife, también nos vino impuesta por otra singular fuente. En esta ocasión, nos topamos con un "Boletín de la Estadística Muni- 
cipal de Santa Cruz de Tenerife" 15 que recogía, detallando por grupos de edad, sexo, profesión y nacionalidad, ${ }^{16}$ el movimiento mensual de pasajeros de la Isla con América desde enero de 1915 hasta julio de 1918, con la única omisión de los datos de noviembre de 1917. Aunque las cifras exceden la masa poblacional objeto de nuestra atención, pues recogen a todos los viajeros incluyendo hasta los extranjeros, ello no les resta representatividad e interés ante la abrumadora mayoría que suponían los emigrantes y la escasez de fuentes alternativas. ${ }^{17}$ Dada la riqueza y densidad de la información recabada, de inmediato nos planteamos abordar un estudio de la emigración isleña ajustado al período de edición del boletín, conformando los años de la guerra europea el espacio temporal de contornos nítidos deseado. Luego, tras comprobar que los otros puertos canarios habilitados para expedir emigración - el de Santa Cruz de La Palma y el de La Luz en Gran Canaria- carecían de series parangonables a la antedicha, no tuvimos más remedio que constreñir, a su vez, el ámbito espacial de la investigación al radio de acción del puerto de Santa Cruz de Tenerife. En definitiva, nuestra fuente nos recrea la composición de la emigración canaria del momento en base a una muestra que incluye al $40 \%$ de los emigrantes.

\section{Fuentes complementarias}

Con el ánimo de hacernos con información cualitativa diversa de cara a disponer de un marco adecuado donde interpretar los fríos datos del boletín, recurrimos a la prensa que en su día emergió y circuló en el contexto geográfico objeto de la propia investigación, esto es, aquélla que llegó a manos de los propios emigrantes y que muy bien pudo recoger, y difundir, el

15 Se trata de una publicación sumamente singular en su época, dado que las Islas aún estaban inmersas en etapas pre-estadísticas, pues además del movimiento de pasajeros de la Isla recoge un cúmulo de datos de la más diversa índole. Dado que la ciudad de Soria alumbró en 1913 un boletín estadístico similar (Pérez-Rioja, Antonio José: "La Prensa en Soria", en La prensa española durante el siglo XIX, Almería, 1987, pág. 90), acaso estemos hablando de un tipo de publicación generalizada en la época por las capitales provinciales del Estado.

16 Por consiguiente, debe tratarse de las cifras que recababan las direcciones de sanidad en los distintos puertos mediante el impreso oficial que al efecto exigían cumplimentar a los capitanes de los barcos. En el caso de Santa Cruz de Tenerife, pues, una vez recopiladas por el jefe provincial de estadística, fueron publicadas en el mencionado boletín antes de remitirlas a Madrid para su publicación, en unión con las de otras provincias del Estado, por el Instituto Geográfico y Estadístico.

17 Además, como podemos desagregar los pasajeros extranjeros y las salidas por los puertos de países vecinos eran nulas dado el entorno insular de nuestro contexto de estudio, inconvenientes imposible de soslayar en esta fuente a nivel estatal, los datos específicos recabados por nosotros sobre el puerto de Santa Cruz de Tenerife adquieren mayor interés aún (Maluquer de Motes, Jordi: Nación e inmigración: los españoles en Cuba (ss. XIX y XX), Gijón, 1992, págs. 110 y 111). 
testimonio de alguno de ellos. Dado que por entonces el periodismo isleño estaba inmerso en etapas típicamente ideológicas, consideramos oportuno recurrir a periódicos de todas las tendencias políticas del momento con el ánimo de agenciarnos otras tantas atalayas desde las que atisbar, con la suficiente amplitud de miras, la realidad objeto de estudio. En el proceso observamos que junto a la información cualitativa deseada, llegaban a nuestras manos guarismos de la más diversa índole, la mayoría fragmentarios y muy desiguales, pero todos útiles como contrapunto a los datos del boletín. Luego, tras someter la información recabada a una fuerte criba mediante un cruzamiento general que nos depuró los datos distorsionantes o, simplemente, inservibles de cara a nuestros objetivos, nos dispusimos a engarzar todas las piezas, como si de un puzzle se tratara, para entrever la realidad.

Dada la necesidad de precisar al máximo el volumen real de la emigración en aras a dilucidar la dinámica de las supuestas idas y venidas a Cuba, consideramos imprescindible hacernos, esta vez mediante fuentes bibliográficas, ${ }^{18}$ con la cuantificación de emigrantes (los pasajeros que viajaban en tercera clase a América) del Consejo Superior de Emigración. En principio, pues, las cifras del boletín deben pecar por exceso, porque recogen a los viajeros de todas las categorías y nacionalidades, mientras que las del Consejo Superior de Emigración deben hacerlo por defecto, porque sólo recoge a los españoles de tercera cuando algún emigrante muy bien pudo viajar en categoría superior. Entre ambos márgenes, pues, debió bascular la emigración del momento, evidentemente, descontando los traslados clandestinos que, como hemos adelantado en párrafos precedentes, fueron insignificantes a pesar de su tradicional magnificación en la historiografía isleña. Dado que los recuentos de la inmigración en Cuba, el principal destino del éxodo isleño del momento, omitieron las cifras canarias entre 1911 y $1916,{ }^{19}$ ni que decir cabe de la importancia de nuestras fuentes. Veamos si somos capaces de operar con ellas para llegar a un nivel de concreción aceptable.

\section{Metodología}

En nuestro afán por precisar lo más posible el número real de migraciones en ambos sentidos, operamos con todos los datos que llegaron a nuestras manos, año a año, para luego, a la luz de la información cualitati-

18 Macías: “Un siglo de emigración...”, págs. 189 y 190, nota n. ${ }^{\circ} 77$.

19 Sánchez Alonso, Blanca: Las causas de la emigración española, 1880-1930, Madrid, 1995, pág. 117. 
va y del índice corrector que demandan los traslados clandestinos, proceder a concretar el número real de migraciones, que no de migrantes, a lo largo de todo el período objeto de estudio. A renglón seguido valoramos el porcentaje que nunca pudo llevar a cabo una emigración golondrina, tanto de los que hicieron definitiva su expatriación, ${ }^{20}$ como de los que quedaron atrapados en América tras emigrar, legalmente, ${ }^{21}$ huyendo del oneroso servicio militar, en espera del oportuno indulto del gobierno. A sabiendas de que las cifras recogen viajes, y no viajeros, sin perder de vista tales limitaciones procedimos a dar hipotéticos porcentajes a los emigrantes golondrina para, una vez contabilizadas en una sola ocasión las emigraciones reincidentes, deducir el número real de emigrantes. ${ }^{22}$ Al final, las cifras nos demostraron que de haber existido emigración golondrina a Cuba, ésta tuvo que ser una modalidad enormemente restringida y marginal, en tanto el volumen real de la emigración canaria del momento debió alcanzar cotas desconcertantemente bajas. Luego, los datos económicos y otros más diversos de índole cualitativa, se encargaron de demostrarnos que, en efecto, la emigración golondrina a Cuba sólo pudo ser un espejismo que percibieron, y nos legaron, los contemporáneos.

Pero de momento, veamos a cuanto ascendieron las migraciones, insistimos que no los migrantes, del período objeto de estudio.

\section{Evolución general del movimiento migratorio}

\section{Las salidas}

En principio, los datos mensuales de los sucesivos años aludidos en el boletín descubren un ritmo migratorio introanual muy desigual, aunque de evolución reiterativa, pues la emigración siempre alcanzaba su cenit en torno al otoño para, en los meses previos y posteriores, registrar una paulatina inflexión que culminaba en la primavera. Las diferencias entre el montante emigrado en una y otra estación son tan acusadas, que las cifras

20 En torno a un 30\% (Yanes: La emigración del municipio..., págs. 68 y 69).

21 En efecto, dejando en evidencia ciertas tesis que adolecen del más mínimo rigor, hemos demostrado que la correlación de los términos prófugo/emigrante clandestino carece de todo fundamento (Yanes: En torno a la importancia...”, págs. 157-174).

22 Evidenciando que eran más los que partían que los que regresaban, las cifras del "Boletín de la Estadística Municipal de Santa Cruz de Tenerife" recogen que entre enero de 1915 y mayo de 1918, sin contar los datos de noviembre de 1917, hubo un total de 8.752 salidas y 5.623 retornos. Los porcentajes atribuibles a la emigración golondrina, evidentemente, de ninguna manera pueden superar las cifras anuales mínimas de los retornos. 
específicas de los meses de octubre, noviembre y diciembre tienden a multiplicar por seis a las de abril, mayo y junio. ${ }^{23}$ Indudablemente, el comienzo y la finalización de las zafras azucareras en $\mathrm{Cuba}^{24}$ tal y como han comprobado todos los investigadores que han estudiado la emigración canaria del momento, ofrecen una explicación más que satisfactoria a tal inarmonía introanual. En lo que discrepamos es en que sean los mismos los que partían todos los años. Pero previamente veamos a cuanto ascendió la emigración en cada uno de aquellos penosos años.

Según dejan entrever las estadísticas del Consejo Superior de Emigración, en vísperas del estallido de la guerra, la emigración por el puerto de Santa Cruz de Tenerife estaba en regresión desde el bienio 1910-1911, ${ }^{25}$ cuando de las Islas había salido una riada de isleños disparada por una "pertinaz", en palabras de los periódicos de entonces, sequía. La paulatina contracción de la emigración en años sucesivos al compás que marcaba la mejora del régimen de lluvias, por lo demás, remarca la fuerte incidencia que siempre tuvo la coyuntura del policultivo de subsistencia en la resolución de los isleños a emigrar, ${ }^{26}$ lo cual no podía ser de otra manera dada la magnitud de la población activa isleña encuadrada en el sector primario.

Tal tendencia, sin embargo, cambió bruscamente en 1915 por la coincidente presión que, en sentido contrario pero con efectos concomitantes para el éxodo, ejercieron los factores de atracción en Cuba y de expulsión en Canarias a instancias de un mismo detonante: la guerra europea. En

23 En alguna ocasión, sin embargo, encontramos menor emigración en meses colindantes a octubre, noviembre y diciembre que en otros distantes, tal y como ocurrió a comienzos de 1918, cuando a los 70 pasajeros de enero siguieron nada menos que 264 en febrero. Para comprobar si tal anomalía respondía o no a la realidad, recurrimos a la prensa de la época, donde confirmamos que, en efecto, la emigración en enero de aquel año alcanzó cifras muy inferiores a las de febrero por la no admisión de pasaje del Reina Cristina cuando pasó por Santa Cruz vía La Habana abarrotado de emigrantes peninsulares (El Progreso de Santa Cruz de Tenerife y Gaceta de Tenerife, 31 de enero de 1918). Tal circunstancia, por lo demás, corrobora la fiabilidad de nuestra fuente.

24 Por las razones comentadas en la nota anterior y por la propia evolución de la coyuntura isleña a instancias del sector de subsistencia, los contornos de la afluencia anual a Cuba no eran necesariamente nítidos. Normalmente, los inicios de la avalancha eran claramente perceptibles desde septiembre, a veces desde agosto e, incluso, aunque muy tímidamente, desde julio. El otro extremo, esto es, el cese de la riada humana, alguna vez se hizo esperar hasta febrero, tal y como ocurrió en 1918.

25 En efecto, desde 1911 a 1914, el número de isleños que emigró por el puerto de Santa Cruz de Tenerife según el Consejo Superior de Emigración, ascendió a 3.674, 2.8582 .838 y 1.894, sucesivamente (Macías: “Un siglo de emigración...”, págs. 189 y 190, nota n. ${ }^{\text {777). }}$

26 Tal circunstancia, con una evolución interanual tan desigual, porque años de sequía y de lluvias bonancibles con sus efectos inmediatos sobre las economías campesinas se sucedían, y aún se suceden aunque pasando desapercibidos por la terciarización y la modernización de la economía isleña, sin otra consideración, da cuerpo a otro argumento que contradice la práctica de la emigración golondrina. 
efecto, la inmediata recuperación de la economía cubana por la revalorización del azúcar en el mercado internacional ante la paralización de la producción remolachera de Europa, cuando la economía canaria entraba en un profundo atolladero por el hundimiento de los sectores portuario y frutero, precipitaron el comienzo de una nueva oleada de emigración por el puerto de Santa Cruz de Tenerife. Datos de procedencia incierta esgrimidos por los contemporáneos, cuantificaban el éxodo de 1915 en 2.591 emigrantes; ${ }^{27}$ mientras el Consejo Superior de Emigración elevaba su cómputo a 2.713. Por su parte, el "Boletín de la Estadística Municipal de Santa Cruz de Tenerife" hablaba, una vez descontados los 209 extranjeros, de un total de 2.854 pasajeros salidos aquel año hacia América.

El contraste de los diversos guarismos deja entrever que en 1916 el contingente de emigrantes que partió por el puerto de Santa Cruz de Tenerife debió moverse a niveles muy similares a los del año anterior. Esta vez, mientras el Consejo Superior de Emigración hablaba de 2.690 emigrantes, el recuento de pasajeros hacia América del "Boletín de la Estadística Municipal de Santa Cruz de Tenerife", una vez desagregados los 141 extranjeros, ascendía a 2.722 .

En 1917, la oleada de emigración del período objeto de estudio alcanzó su momento culminante sin impedir tal evolución la inestabilidad que sufrió Cuba aquel año por la incidencia de factores tan diversos como la revuelta liberal de comienzos de año, la entrada en la guerra del lado aliado y la posterior huelga general de los braceros por el envilecimiento de los jornales ante la masiva contratación de antillanos. En esta ocasión, mientras las cifras del Consejo Superior de Emigración hablaban de 3.146 emigrantes, los datos del "Boletín de la Estadística Municipal de Santa Cruz de Tenerife", restando los 78 extranjeros y con la omisión de los datos de noviembre, arrojaban un total de 2.594 pasajeros en los once meses restantes del año.

En el último año bélico, la oleada emigratoria objeto de estudio conoció un claro retroceso, si bien, esta vez carecemos de datos globales que nos permitan poner topes a la cuantificación porque, de un lado, el Consejo Superior de Emigración no publicó las cifras de 1918 y, de otro, el "Boletín de la Estadística Municipal de Santa Cruz de Tenerife" cesó a mediados de año. La única referencia cuantitativa global, las salidas de pasajeros españoles por los puertos canarios hacia todos los destinos, deja entrever el

27 Rodríguez González, Leoncio: Tenerife. Impresiones y comentarios, Santa Cruz de Tenerife, 1916, pág. 154. 
alcance de la contracción, pues arroja la raquítica cifra de $3.316,{ }^{28}$ esto es, tan solo rebasaba en unos escasos centenares a los emigrantes que, según el Consejo Superior de Emigración, habían partido el año anterior del puerto tinerfeño. Los datos parciales del "Boletín de la Estadística Municipal de Santa Cruz de Tenerife", al recoger que entre enero y mayo de 1918, una vez descontados los 54 extranjeros, partieron 582 pasajeros hacia América, evidencian que en el segundo semestre del año la emigración debió registrar un parón en seco.

En efecto, la prohibición de la emigración por los puertos canarios tras la expansión de la epidemia gripal, precisamente, cuando era inminente el comienzo de la zafra azucarera cubana, junto al deterioro de la imagen de Cuba ante los continuos conflictos del año anterior y las amplias expectativas sociales que levantó en las Islas el cese de las hostilidades, bastan para explicar la retención del flujo emigratorio en la segunda mitad del año. Pero al siguiente, una vez levantada la veda, la inmediata frustración de las perspectivas de los sectores portuario y frutero de la economía isleña ante la problemática recomposición de las relaciones bilaterales de los países europeos y, en mayor medida aún, la reaparición de la temible sequía $^{29}$ en las Islas, todo ello cuando el sector azucarero en Cuba alcanzaba su apogeo, desató otra, la última y más nutrida, avalancha emigratoria a Cuba, cuyos márgenes temporales exceden los límites del período que nos hemos propuesto analizar.

Con el ánimo de aproximar al máximo la dimensión de la oleada que partió del puerto de Santa Cruz de Tenerife en los duros años de la guerra europea, los datos manejados nos vislumbran cifras que rebasan levemen-

28 Pasajeros nacionales salidos por todos los puertos canarios y en todas las direcciones en los años de la guerra europea: 5.430 en 1914, 7.356 en 1915, 9.058 en 1916, 6.512 en 1917 y 3.316 en 1918 (Macías: "Un siglo de emigración...”, pág. 193).

29 La sequía siempre fue el mayor detonante de la emigración isleña, tal y como evidencia que en 1911, cuando el sector frutero-portuario funcionaba con plena normalidad, emigraran varios centenares de isleños más que en 1917, cuando el sector exterior de la economía isleña había caído en un profundo marasmo. La mayor carestía de los pasajes no es una explicación satisfactoria porque en 1919, cuando eran más caros aún, otra "pertinaz" sequía expulsó a una masa de población superior, incluso, a la de 1911. Dada la enorme cantidad de población isleña que dependía del policultivo de subsistencia, hasta años bastante recientes, cuando se aceleró la terciarización de la economía isleña con el desarrollo del turismo, no es posible estudiar cualquier coyuntura económica isleña sin prestar una privilegiada atención a la evolución coyuntural del régimen de lluvias en las Islas (Yanes: Leoncio Rodríguez y “La Prensa”..., págs. 183-191). Por consiguiente, los análisis históricos hasta ahora efectuados sobre la economía isleña, más aún de aquéllos centrados en las etapas más remotas, en los que se intenta forzar explicaciones integrales en función de la evolución de las exportaciones del sector exterior, nos parecen, como mínimo, poco fiables para conocer las vivencias cotidianas de los isleños. 
te las diez mil emigraciones, que no emigrantes, pues muchos individuos pudieron viajar en varias ocasiones tras otros tantos regresos y figurar, por consiguiente, varias veces en las estadísticas, asunto cuya dilucidación justifica la redacción de las presentes líneas. Dado que el volumen de las salidas clandestinas, tradicionalmente magnificado en la historiografía isleña, en buena medida por la insensata consideración de los prófugos como presuntos emigrantes clandestinos ${ }^{30}$ y por el desconocimiento de la infraestructura de comunicaciones Canarias-América, ${ }^{31}$ en modo alguno pudo alcanzar siquiera el 5\% de las legales, su incidencia en las estadísticas debió estar contrarrestada por el montante que suponían los viajeros que no eran emigrantes.

\section{Los retornos}

Para calibrar el volumen real de los retornos, tan sólo disponemos de las cifras del "Boletín de la Estadística Municipal de Santa Cruz de Tenerife" que, como sabemos, exceden a las de los emigrantes retornados porque aluden al total de viajeros. Según éstas, entre enero de 1915 y mayo de 1918, con la conocida omisión de los datos de noviembre de 1917, el puerto tinerfeño presenció la entrada de un total de 5.623 pasajeros procedentes de América, cifra que supone un $62 \%$ del contingente que entre los mismos márgenes temporales viajó en sentido contrario. En esta ocasión, los traslados clandestinos, que también los hubo aunque la historiografía canaria los haya obviado en la misma medida que ha magnificado los homólogos de dirección opuesta, ${ }^{32}$ debieron alcanzar cotas tan insignificantes que nunca pudieron contrarrestar, en modo alguno, el porcentaje de los viajeros que no eran emigrantes retornados. En este caso, pues, el "Boletín de la Estadística Municipal de Santa Cruz de Tenerife" ofrece una cuantificación más alta, aunque no en exceso, de la real.

30 Tal impresión, pues no es otra cosa que eso, es el eco actual de valoraciones cualitativas de la época hasta ahora no verificadas con la oportuna investigación científica a posteriori (Yanes: "En torno a la importancia...”, págs. 157-174; y Crisis económica y emigración..., págs. 69-76).

31 Yanes: Crisis económica y emigración..., págs. 44-57. Sacando a la luz tal circunstancia, evidenciamos la limitación de las cifras de la emigración canaria.

32 En alguna ocasión, el gobernador civil de la provincia dio al jefe de la policía local instrucciones para que extremara las precauciones en orden a evitar el desembarco de polizones en Santa Cruz para mitigar el problema de la mendicidad. Pero el problema era insoluble porque los polizones bajaban a tierra entremezclados con los pasajeros, lo que hacía imposible su detección, y más aún de los isleños por el inmediato amparo que encontraban en sus familias (El Progreso, 14 de febrero de 1916, pág. 1). 
Las cifras de los retornos experimentaron un decidido incremento conforme avanzaron aquellos duros años induciendo, cuando a simple vista son contempladas, a una interpretación errónea pues, en efecto, guardando coherencia con la evolución de las de signo contrario, parecen ser fruto de una emigración golondrina, cuando la propia coyuntura cubana ofrece explicaciones más que satisfactorias a tal evolución. Así, a los 1.382 retornos de 1915 siguieron los 1.826 de 1916 y los 2.045 de 1917, éstos últimos sin contar los datos de noviembre. El grueso de todos ellos, por lo demás, se agolpan en los meses que presenciaban la finalización de las zafras, lo cual no podía ser de otra manera dado que tal era la ocupación de la mayoría de los emigrantes isleños. Otra cosa es suponer, sin base científica alguna, que los isleños iban a Cuba a trabajar en una sola zafra.

\section{Resultados de la investigación}

\section{La evidencia de la inviabilidad de la emigración golondrina}

$\mathrm{Al}$ margen de comprender una reducción en un $38 \%,{ }^{33}$ la composición del contingente que llegó a Tenerife procedente de América difiere de la del que viajó en sentido contrario en un grado suficiente como para evidenciar que, en efecto, unos y otros no eran los mismos todos los años. En principio, el notorio incremento de la proporción de hombres sobre mujeres en el contingente retornado, un $87 \%$ frente a un $13 \%$, lo que supone nueve puntos más respecto a las cifras del contingente antagónico, delatan que, en efecto, las mujeres no practicaron la emigración golondrina. Los regresos de los hombres, además, se agolpaban al término de las zafras, cuando alcanzaban porcentajes que superaban el $90 \%$ en relación a las mujeres que retornaban con ellos. Ahora bien, el problema estriba en saber si los hombres que partían y regresaban de las zafras azucareras eran los mismos todos los años.

33 Tal porcentaje resulta engañoso de cara a concretar el volumen real de los retornos de la emigración canaria del momento que, según comprobamos en nuestro estudio sobre el microespacio de Güímar, debemos incrementar hasta un 70\%. Al respecto conviene valorar, de un lado, que en las mencionadas cifras figuraban algunos de los isleños que habían emigrado antes de la guerra y, de otro, que los retornos más cuantiosos acontecieron en los años 20 (Yanes: La emigración del municipio..., págs. 68 y 69). 
La comparación por grupos de edad entre ambos contingentes, nos evidencia que un sector notable de los hombres tampoco pudo practicar la emigración golondrina. En efecto, la población que oscilaba entre los 9 y los 19 años, aquélla que nutría hasta un 34\% de las salidas, apenas suponía un $7 \%$ de los regresos. Para mayor contraste, entre éstos, y también en contraposición a los que emigraron, había más población próxima a los 9 que a los 19 años..$^{34}$ La práctica desaparición de la población joven y adolescente del contingente retornado, está paliada con un incremento no menos espectacular en la que iba desde los 20 a los 59 años hasta alcanzar un $83 \%$, cuando tal grupo de edad sólo había aportado el 56\% de las salidas. En definitiva, la juventud isleña prolongaba su estancia en América los suficientes años como para alcanzar la adultez.

La inviabilidad de las supuestas idas y venidas anuales a Cuba del sector joven y adolescente de los emigrantes canarios, que representaba nada menos que un tercio del contingente total, derivaba de sus problemas militares, pues había emigrado legalmente, como hemos matizado con reiteración, al amparo de la generosa legislación migratoria a edades muy tempranas con el propósito de eludir el oneroso servicio militar del momento. En efecto a tales edades no procedía regresar a Canarias al término de la zafra, por el riesgo de quedar atrapados por el servicio militar si el gobierno hacía uso del articulado de la legislación que preveía la retención de mozos, circunstancia que suponía el encarcelamiento militar una vez cumplidos los 21 años, cuando eran declarados prófugos por incomparecencia al llamamiento a filas. Por consiguiente, ni las mujeres ni el sector joven y adolescente de los hombres practicaron la emigración golondrina. ¿Tal práctica era patrimonio de los hombres adultos?.

Veamos como tampoco. En efecto, circunstancias de muy diversa índole que afectaban a toda la población emigrante, insisten en la inviabilidad de la emigración golondrina. Tal es el caso de un detonante tan decisivo, acaso, el más determinante, para la emigración como la sequía que, dada su incidencia coyuntural y arrítmica, de ningún modo pudo desenca-

34 En efecto, según traslucen las esporádicas noticias de la prensa de la época que daban cuenta de la llegada a Santa Cruz de pasajeros procedentes de América, buena parte de la población de este tramo de edad llegaba a las Islas en el seno de familias nucleares, la inmensa mayoría, procedentes de Buenos Aires, Montevideo y, en menores proporciones, de otros puertos de las repúblicas continentales. Dado que la población de edad similar que emigró en aquellos años iba a título individual, tal y como hemos constatado en el microespacio de Güímar, para acudir a las zafras cubanas, deducimos que, en efecto, los que partieron con edades comprendidas entre los 9 y los 19 años eran mayores que los homólogos que regresaron. 
denar idas y venidas anuales a Cuba. En el otro sentido, y en esto también hay que incluir a todos los emigrantes, a las menguadas cifras de los hipotéticos emigrantes golondrina habría que descontar el porcentaje de los isleños que emigró con el propósito de establecerse en América, los cuales representaron un porcentaje que rondaban el $30 \%$.

Pero es más, a poco que reflexionemos sobre los datos del "Boletín de la Estadística Municipal de Santa Cruz de Tenerife", evidenciamos que la tan cacareada emigración golondrina no pudo ser otra cosa que un fenómeno aparente. En efecto, dado que las cifras recogen, en números redondos, unas diez mil salidas y unos seis mil retornos, ${ }^{35}$ aceptando que la emigración golondrina tan sólo era marginal, esto es, que era practicada por mil emigrantes (cifra que, en todo caso, nunca pudo superar a la luz de las llegadas anuales de los pasajeros de América), tendríamos acaparados cuatro mil viajes de ida y vuelta en nuestro período de estudio, lo que rebajaría la cifra de emigrantes reales a siete mil salidos y tres mil retornados, una vez descontados en ambas series los viajes de los pasajeros reincidentes. $\mathrm{Y}$ es que las estadísticas, como hemos matizado con reiteración, recogen migraciones y no migrantes, lo que significa que si damos por buena la existencia de la emigración golondrina, no tenemos más remedio que recortar el número de emigrantes reales, y tanto más conforme magnifiquemos la incidencia de tal tipo de migración. Lo insólito es que quienes han defendido la existencia de la emigración golondrina hayan sido los que han propuesto las cifras más altas para la emigración isleña de la época, superiores a los 50.000 emigrantes para el quinquenio 1915-1920, ${ }^{36}$ circunstancia que supondría una cantidad exorbitante de viajes de ida y vuelta a Cuba, inviables a la luz de las comunicaciones de la época. Y tal realidad llegaría a extremos histriónicos si, en lugar de los cuatro años de la guerra europea, consideráramos todo el tramo inicial del siglo actual.

En definitiva, si defendemos el carácter golondrina de la emigración canaria del momento, no nos queda otro remedio que aceptar cifras espectacularmente bajas para el número real de emigrantes. Defender, a un tiempo, ambas características en la emigración isleña del momento es, cuanto menos, un despropósito.

35 Yanes: Crisis económica y emigración..., págs. 44-58. Al respecto conviene insistir en las limitaciones de la infraestructura de las comunicaciones Canarias-América, que en modo alguno pudieron permitir un mayor volumen de desplazamientos.

36 Macías: “Un siglo de emigración...”, pág. 198. 


\section{Un argumento económico que insiste en la inviabilidad de la emigración golondrina}

Una somera aproximación a las diferencias salariales existentes entre ambos espacios insulares en los años de apogeo del sector azucarero cubano, insiste en la inviabilidad de la afluencia anual y reiterativa de los jornaleros isleños a Cuba. En efecto, las cifras, ponderadas con datos cualitativos de la época de indudable importancia, aunque de difícil concreción, cantan por sí solas.

A la finalización de la guerra europea, el abanico de los jornales agrícolas en Canarias iba desde las 3,5 pesetas del Valle de La Orotava, a las escasas 2 pesetas de las áreas más deprimidas del Archipiélago ${ }^{37} \mathrm{El}$ tradicional autoabastecimiento de las familias isleñas, ${ }^{38}$ paliaba la escasa cuantía de los ingresos monetarios de la época. En la Cuba de entonces, según el Partido Comunista de la isla antillana, el abanico salarial de los centrales azucareros basculaba entre los 90 centavos y los 2,50 pesos. ${ }^{39}$ Suponiendo a la moneda cubana paridad con la norteamericana, tales cifras suponían, en términos de la época, unas respectivas 4,66 y 12,96 pesetas. ${ }^{40}$ En principio, pues, las diferencias salariales resultaban notorias.

Pero para valorar el incremento real del beneficio que reportaba a los jornaleros canarios el desplazamiento a Cuba, tenemos que ponderar otros factores al margen de los escuetos jornales. Es el caso de la duración de las zafras que, encima de limitadas a períodos muy concretos, cada vez concluían con mayor celeridad. Así, en aquellos años, el promedio anual de días de trabajo bajó desde los 156,7 de 1919 a los 126,8 de 1924. ${ }^{41}$ Haciendo cuentas, tenemos que un jornalero trabajando los días promediados en 1919 a los salarios mencionados, percibiría al año, en un caso, pensamos que en la inmensa mayoría a la luz del bajo nivel socioprofesional de los emigrados, 590,88 pesetas; y en el otro, 2.030,83 pesetas. Evidentemente, los nive-

37 Brito González, Oswaldo: Historia del Movimiento Obrero Canario, Madrid, 1980, pág. 203.

38 En efecto, incluso en las áreas más urbanizadas del Archipiélago, caso de Santa Cruz de Tenerife, por entonces era habitual que la mayoría de las familias cubriera buena parte de sus necesidades alimentarias a instancias de animales domésticos y de algún pedazo de terreno en régimen de policultivo.

39 Instituto de Historia del Movimiento Comunista y de la Revolución Socialista de Cuba anexo al Comité Central del Partido Comunista de Cuba: Historia del Movimiento Obrero Cubano 1865 1958), La Habana, 1987, tomo I, pág. 273. Se trata de un abanico salarial que estuvo vigente hasta noviembre de 1922.

40 Para deducir tal cuantía recurrimos al tomo 22 de la Enciclopedia Espasa-Calpe, pág. 576, editado en 1924, que fijaba el cambio del dólar en 5,1826 ptas.

41 Le-Riverend, Julio: Historia Económica de Cuba, La Habana, 1974, pág. 586. 
les reales de ingresos debieron bascular entre ambos extremos con una acusada inclinación hacia el inferior. En cualquier caso, había que descontar el precio del pasaje ${ }^{42}$ el porcentaje del jornal que los centrales satisfacían con vales a canjear en sus tiendas, la escasa capacidad de ahorro de los emigrados canarios y, evidentemente, la pérdida del nada despreciable autoabastecimiento marginal en las Islas. En el sentido contrario, la posible realización de otras actividades en los 209 días restantes del año, cosa nada fácil, pues muchos quedaban en el propio central aguardando la nueva zafra subsistiendo, en algunos casos, con préstamos a cuenta de los futuros jornales. En definitiva, las diferencias salariales, ponderadas en el marco de la época, evidencian que el carácter reiterativo y anual no fueron los rasgos dominantes y definitorios de la emigración canaria de entonces.

\section{Conclusiones}

El pormenorizado análisis de la emigración del término municipal de Güímar en su carácter de paradigma de las zonas rurales de las Islas, lo que supone hablar de la inmensa mayoría del espacio insular, nos ha demostrado que los emigrantes emitidos por tales áreas en modo alguno practicaron una emigración golondrina, esto es, de tipo estacional. ${ }^{43}$ Es más, un solo traslado y por espacio de cuatro, cinco y, como mucho, seis años, fueron los rasgos dominantes de la, por lo demás, desigual ${ }^{44}$ emigración canaria de

42 En los años de la guerra europea, al compás de la generalizada inflación del momento, el precio del pasaje a La Habana sufrió un continuo encarecimiento que lo llevó desde las 110 pesetas de anteguerra a las 319 en vísperas del cese de las hostilidades. Por consiguiente, este factor frenó la emigración cuando había más razones, tanto en Cuba como en Canarias, para emigrar (Yanes: Crisis económica y emigración..., pág. 41).

43 En 1930, los recursos poblacionales de Güímar, Tenerife y las Islas Canarias ascendían, respectivamente, a 10.000, 218.877 y 555.128 habitantes. Ahora bien, para ponderar el alcance de las conclusiones, más que a los porcentajes existentes entre aquellos guarismos, debemos atender al carácter representativo de Güímar dentro de los núcleos rurales del Archipiélago.

44 No olvidemos, por caso, el tímido contingente que con un componente más cualificado, empresarial y familiar, y con un carácter más definitivo, recaló por aquellos años en las repúblicas continentales. Este sector, por colateral que resulte ante las notas dominantes de la emigración canaria del momento, pensamos, no debe ser desdeñado en futuros trabajos. En principio, su procedencia de la zona ligada al sector económico de exportación del municipio, en contraposición al que afluía a Cuba que provenía en mayor grado de la zona de subsistencia, con el desigual carácter emigratorio de ambos, el uno esencialmente definitivo y el otro más provisional, ofrece una hipotética explicación a la pérdida de recursos poblacionales de las zonas exteriores frente al mantenimiento demográfico de las tradicionales en aquellos críticos años a nivel de todo el Archipiélago (véanse Burriel de Orueta, Eugenio: Canarias: población y agricultura en una sociedad dependiente, Barcelona, 1982, págs. 73-111; y Yanes Mesa, Julio Antonio: "Modelo económico y emigración en la Historia Contemporánea Canaria", en XI Coloquio de Historia Canario-americana, Las Palmas, 1994 (en prensa). 
las zonas interiores del Archipiélago, siendo muy raros los que repitieron experiencia y anecdóticos los que lo hicieron en años consecutivos, ninguno de los cuales, por lo demás, reiteró en más de dos ocasiones. Factores de muy diversa índole y de incidencia generalizada en todo el Archipiélago, tales como la determinación en la emigración de un detonante tan ocasional e imprevisible como la sequía, ausente, cuando no presente, por espacio de varios años en las Islas; el rechazo de los jóvenes al servicio militar, lo que dejó atrapado en América a un tercio de los emigrantes por espacio de varios años; y los isleños que emigraron con el propósito de hacer definitiva su expatriación, que suponían nada menos que otro tercio del contingente emigrado, insisten en la improcedencia de tal tipo de emigración.

A nivel de macroespacio, una somera reflexión sobre el volumen real de la emigración canaria en su conjunto a la luz de aspectos hasta ahora desatendidos por la historiografía isleña como la dimensión real de los traslados clandestinos y la limitada infraestructura comunicatoria CanariasAmérica, insiste en que las Islas, incluyendo sus áreas más urbanizadas, nunca pudieron emitir tal tipo de emigración, por residual que fuera su porcentaje, a no ser que aceptemos que la emigración canaria del momento alcanzó cifras desconcertantemente bajas. Otro tanto demuestra el contraste de las diferencias salariales que había entre Canarias y Cuba, obviando factores tan determinantes como las mentalidades de la época y la escasa capacidad de ahorro de los jornaleros isleños, en su inmensa mayoría analfabetos. Las insistentes versiones coetáneas del éxodo que, en contraposición a nuestras conclusiones, hablaban de reiteradas idas y venidas anuales de isleños, ${ }^{45}$ pues, debieron configurarse en la propia isla antillana cuando, en efecto, al comenzar las zafras los cubanos veían llegar a muchos isleños $\mathrm{y}$, a su término, marchar a otros tantos. ${ }^{46}$ Pero ello, tal y como hemos observado a nivel de microespacio y deducido a nivel de macroespacio, no fue sino una aparente percepción coetánea, porque unos y otros no eran los mismos, ni a niveles residuales, todos los años.

$45 \mathrm{Y}$ alguna que otra vez llevando hasta el delirio tal realidad, caso del informe del Consejo Superior de Emigración que recogía: “... entre los emigrantes (canarios) no es raro encontrar tipos de psicología singularísima, que rinden al año cuatro o cinco viajes llevando productos hortícolas, para volver con mercancías antillanas..." (texto recogido de Maluquer de Motes: Nación e inmigración..., pág. 109). Evidentemente, tal afirmación, aparte de exagerar lo que debió ser el caso, y muy ocasional, de algún viajero en particular, distorsionó aún más la realidad con la generalización de su práctica.

46 Todo ello, aparte de ilustrar el recelo que nos debe producir toda valoración cualitativa que no esté verificada a posteriori con datos objetivos, nos ilustra magníficamente el riesgo que conlleva la interpretación de cualquier hecho histórico desde su propio contexto y bajo perspectivas coetáneas. 